\title{
Study on Quality Traits for Steamed Bread Made from 25 Representative Wheat Varieties in Shandong Province
}

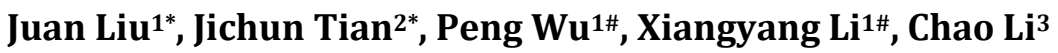 \\ ${ }^{1}$ College of Food Science and Engineering, Shandong Agricultural University/Key Laboratory of Food Processing Technology and \\ Quality Control in Shandong Province, Taian, China \\ ${ }^{2}$ Group of Quality Wheat Breading, Shandong Agricultural University/State Key Laboratory of Crop Biology, Taian, China \\ ${ }^{3}$ Agricultural Environment Protection Station, Taian, China \\ Email: 1728502825@qq.com, "13954847828@163.com, "xiangyang_l@163.com
}

How to cite this paper: Liu, J., Tian, J.C., Wu, P., Li, X.Y. and Li, C. (2019) Study on Quality Traits for Steamed Bread Made from 25 Representative Wheat Varieties in Shandong Province. Agricultural Sciences, 10, 499-507.

https://doi.org/10.4236/as.2019.104039

Received: December 29, 2018

Accepted: April 16, 2019

Published: April 19, 2019

Copyright ( 2019 by author(s) and Scientific Research Publishing Inc. This work is licensed under the Creative Commons Attribution International License (CC BY 4.0).

http://creativecommons.org/licenses/by/4.0/ (c) (i) Open Access

\begin{abstract}
In order to study steamed bread quality traits and explore good wheat cultivars, 25 wheat cultivars grown in Shandong province were used through one-process fermentation procedure to examine the variability of steamed bread quality traits and the correlation between quality and score. The results showed that all the steamed bread quality traits expressed large variable coefficient except volume, $L^{*}$ value, $I^{*}$ value and cohesiveness traits, which suggested that the genetic diversity made from wheat in Shandong province was large. The average comprehensive score of the steamed bread was 76.8 for the tested 25 varieties, and ten varieties reached the good steamed bread level, which were Liangxing 99, Luyuan 205, Jimai 22, Jinan 17, Tainong 19, Wennong 17 , Huaiyin 84137 , and Huaimai 8 . The main quality factors affecting the steamed bread score were volume, $L^{*}$ value, $A^{*}$ value, hardness, chewiness, and adhesiveness. Among these factors, the adhesiveness has a significantly positive correlation with the hardness and cohesive, and the volume has a significantly positive correlation with the $A^{*}$ value. The volume, $L^{*}$ value has a significantly positive correlation with score, $A^{*}$ value, hardness and chewiness, and gumminess has a significantly negative correlation with the score. There was no correlation between the score and other traits. The results will benefit the understanding of steamed bread quality in wheat cultivated in Shandong.
\end{abstract}

\section{Keywords}

Wheat, Steamed Bread, Quality Traits, Variable Coefficient, Correlation Coefficient

Juan Liu and Jichun Tian are the cofirst authors of the article. 


\section{Introduction}

Wheat is one of the most important crops in the world, and its planting area and range are the highest in the world. Shandong province has a vast territory, four distinct seasons, sufficient light time, suitable temperature, and diverse soil types, such as cinnamon soil, brown soil and fluvo-aquic soil, which guarantee the excellent quality of wheat [1] [2] [3]. In addition, Shandong province is a dominant production area for wheat planting in China, accounting for $18 \%$ and $14 \%$ of the country's total output and planting area, respectively. The number of single-yield products has been among the highest in the country for many years [4] [5].

Steamed bread is a traditional staple food in northern China and plays an important role in the dietary structure [6]. Research on the quality of steamed bread has been reported since the 1950s. Up to now, there have been many studies on the quality of wheat flour and the quality of steamed bread at home and abroad [7] [8] [9]. Zhang et al. [10] studied the correlation between the quality of wheat flour produced in Heilongjiang province and the quality of steamed bread. It has been found that the physical indexes such as ash and drop of wheat flour were significantly and negatively correlated with the sensory score of steamed bread. The protein and wet gluten content were significantly and positively correlated with the sensory score of steamed bread. Kang et al. [11] studied the quality of Huanghuai winter wheat steamed bread, the results showed that the coefficient of variation of most steamed bread quality traits was large, and there was a significant positive correlation between flour brightness and steamed bread sensory score; Ban et al. [12] studied the low-gluten wheat variety steamed bread in Hebei. The results showed that there was a significant positive correlation between the height and the stability time of the steamed bread, and the specific volume of the steamed bread was negatively correlated with the quality coefficient of the silt. It can be seen that there was a close relationship between the wheat and the quality of steamed bread, but there are some differences in the quality of steamed bread in different regions. As a main area for wheat cultivation, the study on the quality of steamed bread made from major wheat varieties in Shandong province in recent years has not been reported.

In this study, 25 wheat varieties mainly grown in Shandong province were used as experimental materials. By analyzing the phenotypic variation of the quality traits of steamed bread and the correlation among various traits, the main indicators affecting the quality of steamed bread were discussed, aiming to provide theoretical references for the further improvement of wheat breeding.

\section{Materials and Methods}

\subsection{Materials}

The materials used in this study were all the backbone parents and high generation strains. It was widely planted in Shandong province recently years (Table 1). They were planted in the experimental field of Shandong Agricultural 
Table 1. Wheat varieties used in this study.

\begin{tabular}{cccc}
\hline Variety number & Variety name & Variety number & Variety name \\
\hline 1 & Shannong 55843 & 14 & Jimai 19 \\
2 & Shannong 22 & 15 & Shannong 2 \\
3 & Liangxing 99 & 16 & Jimai 22 \\
4 & Shannong 055849 & 17 & Jinan 17 \\
5 & New Shannong11 & 18 & Yannong 21 \\
6 & Taishan 21 & 19 & Wennong 17 \\
7 & Tainong 18 & 20 & Xizhi 8222 \\
8 & Tainong 9236 & 21 & Yan 99102 \\
9 & Tainong 19 & 22 & Huaiyin 84137 \\
10 & Lumai 14 & 23 & Huai 60182 \\
11 & Huaimai 8 & 24 & D209 \\
12 & Zimai 12 & 25 & \\
13 & Luyuan205 & & Jining 16 \\
\hline
\end{tabular}

University in 2014-2015, during which regular field management was carried out, and no serious pests and diseases occurred. After 2 months, the flour extraction rate was $65 \%$.

\subsection{Test Methods}

\subsubsection{Production of Steamed Bread}

$100 \mathrm{~g}$ of wheat flour were weighted, adding $48 \mathrm{ml}$ of water $\left(38^{\circ} \mathrm{C}\right)$ and $1 \mathrm{~g}$ of dry yeast powder. Then stir it in a blender for $3 \mathrm{~min}$, and wake up in a $38^{\circ} \mathrm{C}$ incubator for $1 \mathrm{~h}(85 \% \mathrm{RH})$. Min molding, wake up at room temperature for $15 \mathrm{~min}$; steamed on a steamer with gauze for $20 \mathrm{~min}$; cover with gauze for $40-60 \mathrm{~min}$. The quality of the steamed bread was measured and its volume was measured by the rapeseed replacement method.

\subsubsection{Sensory Evaluation of Steamed Bread}

The evaluation of steamed bread is based on the Chinese industry standard SB/T 10139-93 and was slightly modified. The score is as follows. The total score is 100 ; specific volume is 20 points; appearance shape is 15 points; color is 10 points; elastic toughness is 20 points; structure is 15 points; sticky teeth is 15 points and smell is 5 points. The score group was consist of 10 people trained with sensory identification experience.

\subsubsection{Determination of the Physical Property Index of Steamed Bread}

The steamed bread was cut into a thickness of $25 \mathrm{~mm}$ in the vertical direction and placed on the texture analyzer. P35 probe was used for compression in the TPA mode [13]; rate before test was $3.00 \mathrm{~mm} \cdot \mathrm{s}^{-1}$, and the test rate was 1.0 $\mathrm{mm} \cdot \mathrm{s}^{-1}$; post-test rate was $1.0 \mathrm{~mm} \cdot \mathrm{s}^{-1}$, and the degree of depression was $50 \%$. 
After the first compression, the probe returned to the starting position and waited for three seconds for a second compression, the measurement was repeated three times and took the average value.

\subsubsection{Determination of the Color of the Steamed Bread}

The color of the steamed bread was divided into surface color and internal color. The surface color depended on the point of the top surface of the steamed bread. The internal color determined on the smooth slice of the steamed bread. Color was determined by colorimeter, expressed by $L^{*} a^{*} b^{*} . L^{*}$ means brightness; $L^{*}=0$ is black; $L^{*}=100$ is white; $a^{*}$ means red and green; $+a^{*}$ means reddish; $-a^{*}$ means greenish; $b^{*}$ means yellowish blue; $+b^{*}$ means yellowish; and $-b^{*}$ means bluish. Among them, the external $L^{*} a^{*} b^{*}$ indicates the surface color of the steamed bread, and the internal $L^{*}$, $a^{*}$, and $b^{*}$ indicates the internal color of the steamed bread.

\subsubsection{Statistical Analysis}

Statistical software SPSS 18.0 was used to analyze the data obtained.

\section{Results and Analysis}

\subsection{Phenotypic Traits of Steamed Bread}

As can be seen from Table 2, except volume, external $L^{*}$ value, internal $L^{*}$ value, cohesiveness and score, the coefficient of variation of the other measured indexes of 25 wheat varieties of steamed bread is greater than $10 \%$, among which, the coefficient of variation of internal $a^{*}$ value is the largest (71.73\%), followed by adhesiveness (50.04\%), and volume coefficient is the smallest (only $2.07 \%$ ). It indicates that the genetic diversity of main wheat varieties in Shandong is relatively rich.

\subsection{Quality Traits and Nutrition Content of Steamed Bread}

According to the evaluation of the quality of steamed bread processed by different wheat varieties, the average score of 25 tested wheat varieties was 76.8, among which, there were 8 varieties above 80 scores, including Liangxing 99, Luyuan 205, Jimai 22, Jinan 17, Tainong 19, Wennong 17, Huaimai 84137 and Weimai 8 , accounted for $22 \%$ of the total number, and the highest score was 86 , which was Liangxing 99 (Table 3 and Table 4).

\subsection{Correlation between Steamed Bread Texture Parameters and Score}

It can be seen from Table 5 that hardness was negatively correlated with resilience and score, and was positively correlated with the adhesiveness and chewiness. The adhesivenes, chewiness and score were negatively correlated. Adhesivenes have extremely significant negative correlation with springiness and resilience, and have extremely significant positive correlation with cohesiveness. 
Table 2. Phenotypic data of qualitative character of steamed bread.

\begin{tabular}{|c|c|c|c|c|}
\hline Indicators & Minimum & Maximum & Average \pm SD & $\mathrm{CV} / \%$ \\
\hline Volume $/ \mathrm{cm}^{3}$ & 70.91 & 77.37 & $73.60 \pm 1.52$ & 2.07 \\
\hline Specific volume $/\left(\mathrm{cm}^{3} \cdot \mathrm{g}^{-1}\right)$ & 1.34 & 2.77 & $1.95 \pm 0.28$ & 10.22 \\
\hline External $L^{*}$ & 62.02 & 86.68 & $81.16 \pm 5.48$ & 6.75 \\
\hline External $a^{*}$ & -2.36 & 0.52 & $-1.31 \pm 0.60$ & 45.80 \\
\hline External $b^{*}$ & 14.65 & 24.25 & $18.99 \pm 2.45$ & 12.91 \\
\hline Internal $L^{*}$ & 51.91 & 83.50 & $74.72 \pm 7.34$ & 9.82 \\
\hline Internal $a^{*}$ & 0.01 & 2.03 & $0.67 \pm 0.48$ & 71.73 \\
\hline Internal $b^{*}$ & 12.99 & 21.47 & $17.92 \pm 2.01$ & 11.22 \\
\hline Adhesivenes & 0.01 & 34.67 & $6.06 \pm 3.04$ & 50.04 \\
\hline Cohesiveness & 0.62 & 0.84 & $0.75 \pm 0.03$ & 7.11 \\
\hline Hardness & 1990.91 & $10,673.95$ & $4971.17 \pm 1627.60$ & 32.74 \\
\hline Springiness & 0.42 & 1.84 & $0.90 \pm 0.17$ & 18.89 \\
\hline Resilience & 0.26 & 0.56 & $0.36 \pm 0.06$ & 16.67 \\
\hline Gumminess & 1855.78 & 8102.41 & $4044.45 \pm 1231.72$ & 30.45 \\
\hline Chewiness & 1432.18 & 5375.08 & $3214.57 \pm 1000.15$ & 29.24 \\
\hline Score & 70.00 & 97.00 & $84.80 \pm 5.85$ & 6.90 \\
\hline
\end{tabular}

Table 3. Wheat cultivars and advanced lines suitable for quality steamed bread and their scores.

\begin{tabular}{ccccccccc}
\hline Cultivars & $\begin{array}{c}\text { Specific } \\
\text { volume }\end{array}$ & $\begin{array}{c}\text { External } \\
\text { shape }\end{array}$ & $\begin{array}{c}\text { External } \\
\text { colour }\end{array}$ & $\begin{array}{c}\text { Internal } \\
\text { structure }\end{array}$ & $\begin{array}{c}\text { Internal } \\
\text { Springiness }\end{array}$ & $\begin{array}{c}\text { Internal } \\
\text { cohesive }\end{array}$ & Odour & $\begin{array}{c}\text { Total } \\
\text { score }\end{array}$ \\
\hline Huaiyin 84137 & 17 & 13.5 & 8.0 & 14.5 & 13.0 & 12.0 & 4.0 & 82.0 \\
Tainong 19 & 16 & 13.5 & 7.5 & 13.5 & 16.0 & 13.5 & 4.5 & 84.5 \\
Luyuan 205 & 17 & 14.0 & 7.3 & 12.5 & 17.0 & 13.5 & 4.0 & 85.3 \\
Jimai 22 & 17 & 13.0 & 7.0 & 13.5 & 17.0 & 13.0 & 4.5 & 85.0 \\
Jinan 17 & 17 & 13.0 & 8.0 & 12.5 & 16.5 & 13.5 & 4.0 & 84.5 \\
Huaimai 8 & 16 & 13.5 & 7.0 & 11.5 & 16.2 & 14.0 & 3.5 & 81.7 \\
Wennong 17 & 17 & 13.0 & 7.0 & 13.5 & 16.5 & 13.5 & 4.0 & 84.5 \\
Liangxing 99 & 17 & 13.5 & 7.5 & 13.5 & 17.0 & 13.5 & 4.0 & 86.0 \\
\hline
\end{tabular}

Table 4. The nutrition content of wheat cultivars.

\begin{tabular}{cccccc}
\hline Cultivars & Protein content & Ash content & Wet gluten content & Gluten index & Sedimentation value \\
\hline Weimai 8 & 12.02 & 0.37 & 2.327 & 0.803421788 & 25 \\
Tainong 19 & 12.18 & 0.51 & 2.546 & 0.725142045 & 24 \\
Luyuan 205 & 12.05 & 0.73 & 2.864 & 0.87537092 & 25 \\
Jimai 22 & 12.04 & 0.54 & 2.816 & 0.85082224 & 29.8 \\
Jinan 17 & 12.52 & 0.51 & 2.696 & 0.883532723 & 29.7 \\
Huaimai 84137 & 12.38 & 0.45 & 2.554 & 0.784662787 & 26.2 \\
Wennong 17 & 12.6 & 0.57 & 2.842 & 0.867549669 & 27.3 \\
Liangxing 99 & 12.21 & 0.62 & 2.921 & 0.853491721 & 24 \\
\hline
\end{tabular}


Table 5. Correlation coefficients between steamed bread grades and TPA traits.

\begin{tabular}{|c|c|c|c|c|c|c|c|}
\hline & Hardness & Adhesiveness & Springiness & Cohesiveness & Gumminess & Chewiness & Resilience \\
\hline Adhesiveness & -0.324 & & & & & & \\
\hline Springiness & 0.263 & $-0.731^{\star \star}$ & & & & & \\
\hline Cohesiveness & -0.302 & $0.780^{\star *}$ & $0.576^{* *}$ & & & & \\
\hline Gumminess & $0.854^{* *}$ & -0.385 & 0.243 & $0.514^{*}$ & & & \\
\hline Chewiness & $0.627^{* *}$ & 0.139 & 0.275 & 0.416 & $0.902^{* *}$ & & \\
\hline Resilience & $-0.562^{\star *}$ & $-0.653^{\star *}$ & $0.852^{\star *}$ & $0.933^{* *}$ & 0.447 & 0.262 & \\
\hline Score & $-0.435^{\star}$ & 0.134 & -0.087 & 0.233 & $-0.454^{*}$ & $-0.406^{*}$ & 0.317 \\
\hline
\end{tabular}

${ }^{*}: P<0.05 ; * *: P<0.01$.

Indicating that the cohesiveness increased with the increase of adhesiveness. Springiness has an extremely significant positive correlation with cohesiveness and springiness, indicating that the cohesiveness and resilience increased with the increase of springiness. Cohesiveness has an extremely significant positive correlation with resilience, gumminess has an extremely significant positive correlation with chewiness, and has a significantly positive correlation with score.

\subsection{Correlation Analysis of Color, Volume and Sensory Score of Steamed Bread}

As shown in Table 6, the main factors influencing the steamed bread score were volume, external $L^{*}$, external $a^{*}$, external $b^{*}$, and internal $a^{*}$, which were significant or extremely significant correlated with the score. There was a significantly positive correlation between volume, external $a^{*}$ and score. The external $L^{*}$ value was significantly and positively correlated with the external $a^{*}$ and external $b^{*}$, and was significantly and positively correlated with the value of internal $a^{*}$ and internal $b^{*}$. The external $a^{*}$ were significantly and negatively correlated with the external $L^{*}$, and the external $a^{*}$, internal $a^{*}$ were significantly and negatively correlated with the score. There was a significantly negative correlation between the external $b^{*}$, internal $b^{*}$ and the score.

\subsection{Correlation Analysis of Volume, Color and Texture Parameters of Steamed Bread}

The correlation between color, volume and texture parameters of the steamed bread was shown in Table 7 . The quality was significantly and negatively correlated with hardness, adhesiveness, and chewiness, and was not significantly correlated with cohesiveness, resilience, adhesiveness, and springiness. Volume is an important index influencing the score, which was negatively correlated with hardness, springiness, cohesiveness, adhesiveness and chewiness. The value of external $L^{*}$ have extremely significant positive correlation with springiness, and was significantly and positively correlated with cohesiveness and chewiness, but there was no significant correlation between internal $L^{*}$ and texture parameters. 
Table 6. Correlation coefficients between steamed bread grades and color traits.

\begin{tabular}{|c|c|c|c|c|c|c|c|c|}
\hline & Weight & Volume & External $L^{*}$ & External $a^{*}$ & External $b^{*}$ & Internal $L^{*}$ & Internal $a^{*}$ & Internal $b^{*}$ \\
\hline Volume & 0.151 & & & & & & & \\
\hline External $L^{*}$ & -0.133 & -0.213 & & & & & & \\
\hline External $a^{*}$ & -0.175 & $0.455^{\star}$ & $0.438^{\star}$ & & & & & \\
\hline External $b^{*}$ & -0.226 & -0.123 & $0.537^{\star}$ & $0.622^{* *}$ & & & & \\
\hline Internal $L^{*}$ & -0.078 & -0.162 & $0.685^{* *}$ & $-0.481^{*}$ & $0.513^{*}$ & & & \\
\hline Internal $a^{*}$ & -0.122 & 0.267 & $0.577^{\star *}$ & $0.836^{* *}$ & $0.592^{* *}$ & $0.581^{* *}$ & & \\
\hline Internal $b^{*}$ & -0.212 & -0.254 & $0.492^{*}$ & $0.768^{* *}$ & $0.643^{* *}$ & $0.605^{* *}$ & $0.713^{* *}$ & \\
\hline Score & 0.134 & $0.572^{\star *}$ & $0.725^{\star *}$ & $-0.653^{* *}$ & $-0.472^{*}$ & 0.235 & $-0.436^{*}$ & -0.170 \\
\hline
\end{tabular}

Table 7. Correlation coefficients between steamed bread TPA and colour traits.

\begin{tabular}{cccccccc}
\hline & Hardness & Adhesiveness & Springiness & Cohesiveness & Gumminess & Chewiness & Resilience \\
\hline Weight & $-0.481^{*}$ & -0.284 & 0.136 & 0.175 & $-0.489^{*}$ & $-0.484^{*}$ & 0.252 \\
Volume & $-0.585^{* *}$ & -0.173 & $-0.627^{* *}$ & $-0.679^{* *}$ & $-0.724^{* *}$ & $-0.722^{* *}$ & -0.234 \\
External $L^{*}$ & 0.132 & 0.163 & $0.624^{* *}$ & $0.430^{*}$ & 0.217 & $0.515^{*}$ & 0.335 \\
External $a^{*}$ & 0.213 & $0.630^{* *}$ & $-0.855^{* *}$ & $-0.748^{* *}$ & -0.289 & $-0.470^{*}$ & $-0.802^{* *}$ \\
External $b^{*}$ & 0.253 & 0.127 & -0.102 & -0.36 & 0.320 & 0.294 & -0.270 \\
Internal $L^{*}$ & 0.157 & 0.185 & 0.117 & 0.136 & 0.242 & 0.241 & 0.110 \\
Internal $a^{*}$ & $0.631^{* *}$ & $0.693^{* *}$ & $-0.832^{* *}$ & $-0.871^{* *}$ & 0.113 & -0.186 & $-0.832^{* *}$ \\
Internal $b^{*}$ & $0.650^{* *}$ & -0.271 & -0.133 & -0.315 & $0.748^{* *}$ & $0.717^{* *}$ & -0.263 \\
\hline
\end{tabular}

There was an extreme significantly negative correlation between the external $a^{*}$ and springiness, cohesiveness and resilience, as well as adhesiveness, which was consistent with the internal $a^{*}$. There was no significant correlation between the external $b^{*}$ and the texture parameters, while the internal $b^{*}$ was positively correlated with hardness, adhesiveness and chewiness.

\section{Discussion}

In this study, steamed bread quality traits made of 25 representative wheat varieties of Shandong province were all showed great genetic diversity, except for volume, external $L^{*}$, internal $L^{*}$, and cohesiveness. It is very beneficial to the genetic improvement of steamed bread, and the potential to improve the processing quality of local wheat steamed bread by the method of genetic improvement is huge.

The correlation analysis between the texture parameters and the sensory score of steamed bread shows that the adhesiveness was the main index influencing the score, which was significantly and negatively correlated with the score. Adhesiveness was significantly and positively correlated with hardness, which indirectly confirmed the significantly negative correlation between hardness and 
score, which was consistent with the results of Zhang Shouhua [14] and Zhang Fangfang [15]. Chewiness was significantly and negatively correlated with the score, which was partially consistent with previous steamed bread quality results [16] [17] [18], indicating that reducing the adhesiveness, hardness and chewiness of steamed bread was conducive to improving the score of steamed bread. The main factors influencing the score of steamed bread were volume, external $L^{*}$, external $a^{*}$, external $b^{*}$ and internal $a^{*}$, among which, volume, external $L^{*}$ and score were significantly and positively correlated, which was consistent with the conclusions of Hu Ruibo [19], Guo Boli [20] and Guo Wuqiong et al. [21]. The higher the volume, the brighter the color, and the higher the score of steamed bread. Therefore, these factors should be taken into account in the production of steamed bread. There was a significantly positive correlation between the values of external $L^{*}$, external $a^{*}$ and external $b^{*}$, but there was a significantly negative correlation between the values of external $a^{*}$ and internal $L^{*}$. Specific reasons need to be further explored.

\section{Conclusion}

Through the study, 8 wheat varieties suitable for making high-quality steamed bread were selected, which were Liangxing 99, Luyuan 205, Jimai 22, Jinan 17, Tainong 19, Wennong 17, Huaimai 84137 and Weimai 8. However, this is only the result of one year's experiment, and it still needs many years' experiment results to accurately evaluate the quality wheat varieties of steamed bread.

\section{Founds}

1) The National Natural Science Foundation of China (No. 31872889); 2) Key R \& D programs in Shandong (2018YYSP029); 3) Funds of Shandong Double Tops Program, PR China (SYL2017XTTD01).

\section{Conflicts of Interest}

The authors declare no conflicts of interest regarding the publication of this paper.

\section{References}

[1] Peng, Q., Guo, S.H., Zhang, X.B., et al. (2012) Evolution in Photosynthetic Characteristics of Wheat Cultivars Widely Planted in Shandong Province since 1950s. Scientia Agricultura Sinica, 45, 3883.

[2] Fan, Q.Q., Chu, X.S., Li, Y.L., et al. (2012) Iron and Zinc Contents in Shandong Wheat Landrace. Journal of Plant Genetic Resources, 13, 138-142.

[3] Chen, F.L., Hu, P., Zhao, X.Y., et al. (2013) Analysis of Quality Properties of Main Wheat Cultivars from Three Cities of Shandong Province in 2012. Shandong Agricultural Science, 45, 16.

[4] Kong, X.X., Zhang, Y., Zhao, D.H., et al. (2016) Noodle Quality Evaluation of New Wheat Cultivars from Northern China Winter Wheat. Acta Agronomica Sinica, 42, 1143-1159. https://doi.org/10.3724/SP.J.1006.2016.01143 
[5] Song, J.M., Dai, S., Li, H.S., et al. (2013) Evolution of Agronomic and Quality Traits of Wheat Cultivars Released in Shandong Province Recently. Science Agricultural Sinica, 46, 1114.

[6] Zhu, F. (2014) Influence of Ingredients and Chemical Components on the Quality of Chinese Steamed Bread. Food Chemistry, 163, 154-162. https://doi.org/10.1016/j.foodchem.2014.04.067

[7] Wenjun, L., Margaret, B., Luca, S. and Brennan, C. (2017) Buckwheat Flour Inclusion in Chinese Steamed Bread: Potential Reduction in Glycemic Response and Effects on Dough Quality. European Food Research and Technology, 243, 727-734. https://doi.org/10.1007/s00217-016-2786-x

[8] Kim, E.-A., Lee, S.-Y. and Lee, Y. (2016) Quality Characteristics of Steamed Rice Bread Prepared with Different Contents of Proteolytic Enzyme. Applied Biological Chemistry, 59, 95-102. https://doi.org/10.1007/s13765-015-0145-4

[9] Zhang, J., Zhang, J., Li, M.Q., et al. (2016) Appropriate Ranges of Important Flour Traits for Making High-Quality Steamed Buns as a Staple Food. Food Science, 37, 36.

[10] Zhang, L.L. and Li, C.L. (2014) Study on the Correlation of Quality between Local Wheat Flour of Heilongjiang and Steamed Breads. Academic Periodical of Farm Products Processing, No. 6, 45.

[11] Kang, M.H., Huang, F., Wang, S.J., et al. (2009) Analysis on the Traits for Steam Bread-Making Quality of Wheat Cultivars Extensively Sown in the Southern Region of Yellow and Huai Valleys in China. Journal of Triticeae Crops, 29, 603.

[12] Ban, J.F., Liu, Y.J., Guo, J.B., et al. (2016) Study on Steamed Bread-Making Quality of Low and Medium Gluten Wheat Cultivars of Hebei Province. Journal of Triticeae Crops, 36, 447.

[13] Han, C.M. (2012) Study on the Preparation and Quality Characteristics of Whole Wheat Flour. Henan Technology University, Zhengzhou.

[14] Zhang, S.H., Chen, Y.X. and Wang, X.L. (2016) Effect of a Fermentation Process on the Quality of Frozen Dough and Steamed Bun. Food Research and Development, $37,93$.

[15] Zhang, F.F., Lv, Y.G., Wang, C., et al. (2013) Study on the Effect of Enzyme Preparation on the Color of Steamed Bread. Journal of Henan University of Technology, No. 3, 60 .

[16] Zhu, F. and Xu, G.W. (2007) Correlations of Wheat Physical and Chemical Properties and Chinese Steamed Bread Quality. Cereals and Oils Processing, 8, 109.

[17] Wang, J., Cheng, J.J., Zhang, B.B., et al. (2017) The Effect of the Powder on the Quality of Steamed Buns. Food Science and Technology, 42, 146.

[18] Dongmin, S., Changhe, D. and Lite, L. (2005) Effect of Endoxylanases on Dough Properties and Making Performance of Chinese Steamed Bread. European Food Research and Technology, 5, 540-545.

[19] Hu, R.B. and Tian, J.C. (2006) Relationship between the Main Qualities of Wheat and the Color of Flour. Journal of Triticeae Crops, 26, 101.

[20] Guo, W.Q., Chen, H. and Zhao, Y.F., et al. (2017) Effect of Compound Bacteria Fermentation on the Quality of Steamed Bread. Food Research and Development, 38, 137.

[21] Guo, B.L., Wei, Y.M., Zhang, G.Q., et al. (2002) Discussion on the Quality Evaluation Method of Steamed Bread. Journal of Triticeae Crops, 22, 9. 